\title{
Laser dentistry in daily practice during the COVID-19 pandemic: Benefits, risks and recommendations for safe treatments
}

\author{
Josep Arnabat-Dominguez, ${ }^{1, A-F}$, Alessandro Del Vecchio ${ }^{2, A-F}$, Carmen Todea ${ }^{3, A-F}$, \\ Kinga Grzech-Leśniak ${ }^{4, A-F}$, Paolo Vescovi ${ }^{5, A-F}$, Umberto Romeo ${ }^{2, A-F}$, Samir Nammour ${ }^{6, A-F}$ \\ ${ }^{1}$ Oral and Maxillofacial Surgery Unit, University of Barcelona, Spain \\ ${ }^{2}$ Department of Oral Sciences and Maxillofacial Surgery, Sapienza University of Rome, Italy \\ ${ }^{3}$ School of Dentistry, Victor Babes University of Medicine and Pharmacy, Timișoara, Romania \\ ${ }^{4}$ Laser Laboratory, Department of Oral Surgery, Wroclaw Medical University, Poland \\ ${ }^{5}$ Department of Medicine and Surgery, Oral Medicine and Laser Surgery Unit, Centro Universitario di Odontoiatria, University of Parma, Italy \\ ${ }^{6}$ Department of Dental Sciences, Faculty of Medicine, University of Liege, Belgium \\ A - research concept and design; $B$ - collection and/or assembly of data; $C$ - data analysis and interpretation; \\ $D$ - writing the article; $E$ - critical revision of the article; $F$ - final approval of the article
}

\section{Address for correspondence \\ Kinga Grzech-Leśniak}

E-mail: kgl@periocare.pl

Funding sources

None declared

Conflict of interest

None declared

Received on September 12, 2020

Reviewed on 0ctober 11, 2020

Accepted on November 18, 2020

Published online on February 26, 2021

Cite as

Arnabat-Dominguez J, Del Vecchio A, Todea C, et al. Laser dentistry in daily practice during the COVID-19 pandemic: Benefits, risks and recommendations for safe treatments. Adv Clin Exp Med. 2021;30(2):119-125. doi:10.17219/ acem/130598

DOI

10.17219/acem/130598

Copyright

Copyright by Author(s)

This is an article distributed under the terms of the

Creative Commons Attribution 3.0 Unported (CC BY 3.0)

(https://creativecommons.org/licenses/by/3.0/)

\section{Abstract}

The COVID-19 pandemic forced dental professionals to cope with an unexpected challenge and caused an abrupt cessation of conventional care practices. The high degree of contagiousness as well as the diffusion of the virus through the air and droplets via respiratory transmission placed dental professionals at top-level risk of contracting and spreading the disease. General recommendations were announced in different countries, including patient distancing, air ventilation, surface and instrument sanitization, and the wearing of suitable masks and shields. However, many dental treatments are performed using lasers, and some specific precautions must be added to conventional procedures to ensure the advantages of this technology to patients because of the particular tissue-matter interaction effects of laser wavelengths. Based on the literature, the authors evaluated all of using laser wavelengths to analyze the risk and the benefits of using lasers in daily dental practice, and to provide safety recommendations during pandemic. An unrestricted search of indexed databases was performed. Laser use effects were categorized into: 1) explosive processes that produce tissue ablation and aerosol formation; 2) thermal actions that create vaporization and smoke plume; 3) photobiomodulation of the cells; and 4) enhanced chemical activity.

Knowledge of the device functions and choice of adequate parameters will reduce aerosol and plume formation, and the application of suction systems with high flow volume and good filtration close to the surgical site will avoid virus dissemination during laser use. In the categories that involve low energy, the beneficial effects of lasers are available and sometimes preferable during this pandemic because only conventional precautions are required. Lasers maintain the potential to add benefits to dental practice even in the COVID-19 era, but it is necessary to know how lasers work to utilize these advantages. The great potential of laser light, with undiscovered limits, may provide a different path to face the severe health challenges of this pandemic.

Key words: safety, dentistry, laser, COVID-19, SARS-CoV-2 


\section{Background}

Coronaviruses are a large family of viruses that cause illness in animals and humans. Several coronaviruses cause respiratory infections in humans and range from the common cold to more severe diseases, such as Middle East Respiratory Syndrome (MERS) and Severe Acute Respiratory Syndrome (SARS). Acute respiratory diseases caused by the new coronavirus SARS-CoV-2 (formerly known as 2019-nCoV) spread across China by the end of 2019 and gained worldwide attention. On January 30, 2020, the World Health Organization (WHO) officially declared the coronavirus 2019 (COVID-19) outbreak a public health emergency of international concern. ${ }^{1}$ The coronavirus pandemic has challenged the activities of health professions around the world in the last 4 months.

The role of dentists in the management of patients and simultaneous prevention of the transmission of COVID-19 is crucial. A continuation of normal dental procedures is not adequate because of the social distancing measures introduced by governments in countries affected by this pandemic. Therefore, routine dental care was suspended, and only emergency dental care is provided. However, patients suffering from systemic diseases, such as diabetes and cardiovascular disease, are more sensitive to this viral infection and its life-threatening consequences. Therefore, the return-to-work care for dental professionals is urgent and fundamental for the population. ${ }^{2,3}$

All healthcare professionals have the moral duty to treat patients in the safest manner to avoid the spread of the virus. The use of lasers in medical and dental practices has become widespread in the past decades, and the benefits of lasers in dental practice are universally recognized and have been reported in the literature for more than 30 years. These advantages should be emphasized and discussed in this particular moment because the adaptation of the laser clinical protocols during this pandemic is essential to ensure the best prevention and safety for patients and practitioners.

All dental laser professionals in the affected countries are involved in preventing the spread of $\mathrm{CO}$ VID-19. Many countries are gradually de-confining and renewing their normal activities. The need to restart regular dental care is rising. Consequently, practitioners who use lasers in their daily practices need clear recommendations.

\section{Objectives}

This short article focuses on the risks and benefits of using some laser wavelengths and provides safety recommendations for various laser treatments in daily practice during the COVID pandemic.

\section{Characteristics of the wavelengths in dentistry: general considerations}

Several laser wavelengths are used in different medical and dental fields. The interaction between laser beams and tissues or matter depends on the wavelength and its absorption parameters. We limit our analysis to the most commonly used lasers on oral hard and soft tissues, such as erbium family lasers (Er:YAG, Er,Cr:YSGG), Nd:YAG (yttrium aluminium garnet) and Nd:YAP (yttrium aluminium perovskite doped with neodymium crystal) lasers, diode lasers or KTP (potassium-titanyl-phosphate) and $\mathrm{CO}_{2}$ lasers, as well as red and near infrared (NIR) lights used for photobiomodulation.

We divided the main tissue and matter interaction effects of the laser wavelengths into the following categories:

1. Explosive process leading to tissue and matter ablation. The high absorption of some wavelengths produces an explosive process in the target hard and soft tissues, which leads to photothermal and photomechanical ablation. Many lasers are in this category, including Er:YAG, Er,Cr:YSGG, Nd:YAP and Nd:YAG lasers action on dark matter and metals.

2. Heat generation leading to the vaporization of soft tissues and fusion followed by the melting of hard tissues. This group includes $\mathrm{CO}_{2}$ lasers $(10.6 \mu \mathrm{m})$, diode lasers (445 $\mathrm{nm}$ and 810-980 nm) and Nd:YAP and Nd:YAG lasers action on soft tissues. The vaporization process of soft tissues produces smoke.

3. Biological photobiomodulation in tissues. Low energy red and NIR light irradiation produces a harmless interaction with cells, improves cell viability, and reduces pain and inflammation.

4. Chemical reaction enhancement. The absorption of laser light enhances chemical reactions and causes the release of free radicals (e.g., antimicrobial photodynamic therapy (aPDT), photoactivated disinfection (PAD), photodynamic inactivation (PDI), and teeth bleaching). Visible light wavelengths are primarily included in this category because of its ability to react with electrons.

Based on those 4 simplified categories, we analyzed the benefits and risks during dental treatments and suggested recommendations for safe clinical protocols of the use of lasers in different fields of dentistry.

\section{Photothermal and photomechanical laser ablation}

An aerosol is a heterogeneous system that consists of solid or/and liquid particles dispersed and suspended in the air. The particle size is between $0.001 \mu \mathrm{m}$ and $100 \mu \mathrm{m}$, and aerosols can contain dust, industrial dust particles, bacteria, microorganisms, and plant spore dust. For example, atmospheric smog, which contains PM 2.5 dust particles, is a "huge" aerosol compared to a virus. PM 2.5 
particulate matter is $2.5 \mu \mathrm{m}$ or less, and the diameter of the SARS coronavirus particles is about $0.08-0.12 \mu \mathrm{m}$. Splatter is a mixture of air, water and/or solid substances that range from $50 \mu \mathrm{m}$ to several millimeters in diameter. Obviously, viruses with these small dimensions easily float in the air.

SARS-CoV-2 persists in aerosols and splatter for up to $3 \mathrm{~h}$, and it has a relatively long half-life of about 1.1-1.2 h. ${ }^{4}$

Aerosols and droplets generated during speech have been implicated in the person-to-person transmission of viruses, and there is great interest in understanding the mechanisms responsible for the spread of COVID-19 in this manner. Speaking generates different sizes of oral fluid droplets that may contain infectious virus particles. Large droplets quickly fall to the ground, but small droplets dehydrate and linger in the air as "droplet nuclei", where they act as an aerosol and expand the spatial extent of the emitted infectious particles. ${ }^{5}$

The transmission of SARS-CoV-2 in humans occurs through 4 different ways:

1) inhalation of infected droplets;

2) close contact with infected person;

3) contact with contaminated surfaces followed by face contact and dissemination; and

4) aerosol transmission of pathogens in closed spaces.

During the earlier SARS outbreak, emergency dental care was provided with advice on strict personal protection, and protocols were recommended to reduce or avoid the production of droplets and aerosols using high volume and power suction. ${ }^{6}$

Several publications reported that dental professionals were at high risk of COVID-19 infection due to close face-toface contact. ${ }^{7}$ Some studies also suggested that COVID-19 was suspended in the air in aerosols that formed during medical procedures or indirectly through saliva in asymptomatic patients. ${ }^{8}$ COVID-19 is about $0.12 \mu \mathrm{m}$ in diameter, and aerosol particle sizes range from $0.001 \mu \mathrm{m}$ to $100 \mu \mathrm{m}$. Therefore, it is mandatory to consider the risk of viral diffusion in aerosols produced by some laser wavelengths.

The Er:YAG and Er,Cr:YSGG lasers induce bubble dynamics, a fragmentation process and tissue ablation through photothermal and photomechanical/photoacoustical mechanisms. ${ }^{9}$ At the beginning of irradiation with erbium lasers, the rapid expansion of the layer of evaporated water leads to an increase in pressure. The fragmentation process occurs with and without plasma formation. In both cases, ablation occurs shortly after the beginning of laser irradiation, and a plume of fine, emulsified material is expelled into the surrounding water. ${ }^{10}$

The ablation process accelerates with increased laser energy, which reduces the thermal side effects. When the energy is increased, the pressure and speed of the ejected material also increases, which creates a larger plasma formation. ${ }^{11}$

The lasers used for oral hard and soft tissue ablation and skin resurfacing are pulsed for short exposures of 1-10 ms (or even less than $1 \mathrm{~ms}$ ). These fast pulses produce a more explosive effect with greater tissue ablation and, consequently, a greater spread of viral particles. ${ }^{12}$ Some authors using erbium lasers demonstrated the dissemination of viable cells, viral genes and infectious viruses using in vitro methods. ${ }^{13}$

Due to the proven potential of COVID-19 transmission, it is even more relevant to maintain safety precautions during dental laser applications, including limiting the use of laser-producing aerosols, except when their use has a strong therapeutic advantage compared with other modalities. The choice of the lowest parameters that allow good clinical effects and a reduction of air-flow is important. An accurate adaptation of the water-air spray during laser ablation to reduce aerosols and viral diffusion must be utilized. The suction system of the dental chair must have a high flow volume. The use of rubber dam isolation is strictly recommended. All laser handpieces and the entire device must be disinfected before and after the treatment. The protection of skin, eyes, mouth, and respiratory tract is essential.

\section{Laser-generated heat leads to vaporization of soft tissues and smoke production}

Some lasers offer several advantages during surgery compared to the scalpel. Due to the nature of the pathological tissue and the anatomical district, better results may be obtained by selecting the most suitable laser device. For example, a $\mathrm{CO}_{2}$ laser $(10,600 \mathrm{~nm})$ is optimal for the excision of very hydrated lesions, such as fibrous lesions, while diode lasers (445 nm, $810 \mathrm{~nm}$ and $980 \mathrm{~nm}$ ) and Nd:YAG (1064 nm) lasers, which have a better coagulating action, may be used for very vascularized lesions or tissues that are rich in vessels with a high amount of hemoglobin and risk of hemorrhage. ${ }^{14,15}$

The factor that unites all of these wavelengths is the utilization of the photothermal effect, because the absorbed laser energy is converted to heat. Therefore, considerable amounts of smoke plume are generated, which necessitate constant suction away from the surgical site. ${ }^{12}$ Several studies suggested that laser-derived vapors contained infectious particles or viral DNA. ${ }^{13}$ Garden et al. detected the presence of human and bovine papilloma virus DNA (HPV and BPV) in laser vapors from warts treated with a $\mathrm{CO}_{2}$ laser, ${ }^{16}$ and Sawchuk et al. showed that laser vaporderived from the excision of bovine papilloma contained infectious particles. ${ }^{17}$ A single case of a laryngeal papillomatosis (HPV type 6 and 11) was detected in a surgeon who previously treated patients with anogenital warts using a Nd:YAG laser. ${ }^{18}$ Garden et al. ${ }^{12}$ presented the possibility that BPV maintained its vitality and potential to infect tissue in the smoke plume produced by the laser beam. Several $\mathrm{CO}_{2}$ laser settings were evaluated, and the laser plume at each laser setting was collected and inoculated into animals. Typical BPV lesions containing BPV developed at all laser settings. These viral tumors confirmed 
the ability of the laser plume to produce infection. Aside from viable viruses, the laser smoke may also contain partially inactive or incompetent viruses. Virus-infected cells and viral genes as far as $6.3 \mathrm{~cm}$ from the point of laser impact and laser debris at distances of up to $100 \mathrm{~cm}$ were described. ${ }^{13}$ However, the lack of HPV DNA in the smoke plume after warts treatment with an Er:YAG laser was reported in $1998 .{ }^{19}$

The literature confirmed that lasers generating smoke during surgical procedures may have infectious potential and pose a significant risk to healthcare providers. Because the presence of 2019-nCoV on the oral mucosa, tongue and saliva was confirmed, the use of photothermal lasers that produce smoke must be performed with caution, using the same precautions that were adopted for treatments that produce aerosols. The concern for laser surgeons and their assistants to inhale the SARS$\mathrm{CoV}-2$ virus via the smoke plume produced by thermal lasers is only theoretic, but likely. Considering several advantages of laser technology in oral soft tissue treatment, it is important to continue its use with the adoption of strict safety precautions for practitioners and assistants, including skin protection with gloves and gowns, eye protection, use of masks (FFP2, FFP3 if possible), and the use of a smoke suction system with a high flow volume and good filtration, positioned at the closest distance from the surgical site to avoid nosocomial viral dissemination. ${ }^{12}$

\section{Lasers inducing biological photobiomodulation in tissue}

Photobiomodulation (PBM) is the medical way to use red or NIR laser light to achieve a chemical- and thermal-free beneficial interaction with tissues and cells. Many studies support its properties of tissue regeneration, wound healing, anti-inflammation, analgesia, and neuroregeneration. ${ }^{20-22}$ Moreover, PBM may also act against microorganisms, such as yeasts, bacteria and viruses. The literature includes several interesting studies about the potential efficiency of PBM directly against microorganisms and indirectly to reinforce the immune response or reduce the damage induced by the inflammatory process. ${ }^{23}$

Tsen et al. ${ }^{24}$ demonstrated damage of the viral capsid caused by the Raman resonance induced by the irradiation of a femtosecond 425-nm low level laser. This particular kind of damage modified the protein structure of viral capsid and induced viral aggregation. The damage to the capsid did not prevent the penetration of viruses into the host cells, but it did not allow the viral envelope to dissolve and transmit the viral genetic message to the nucleus. Therefore, the virus was blocked and remained ineffective in the host cell cytoplasm.

Zupin et al. ${ }^{25}$ investigated the direct and indirect antiviral actions of PBM and demonstrated the efficiency of 2 different PBM protocols using a 445-nm blue laser and a 970-nm NIR on neurological microglia cells infected with Zika virus (ZIKV). In both cases, the PBM irradiation enhanced the vitality of the infected cells and reduced the viral load.

Great interest should be focused on the interesting potential of the so-called transdermal PBM. ${ }^{26}$ This technique displaced the old intravenous laser irradiation and consists of the PBM irradiation of blood via laser application over the surface of the radial artery. ${ }^{27}$ The irradiation of blood induces the production of super oxide dismutase (SOD), which is fundamental in the protection of the cells against the toxic overproduction of reactive oxygen species (ROS). The possibility to vehiculate the beneficial effects of this positive and proven action of PBM to all organs, such as the lungs, which are highly damaged by the COVID-19 infection because of the immune system overreaction, could be very helpful and should open a path of research and clinical applications of unexpected potential.

The application of PBM in daily clinical practice is slowly increasing, with great benefits for clinicians and patients.

The PBM protocols involve the use of red and near-infrared lasers emitting in the so-called "therapeutic window" wavelength between $600 \mathrm{~nm}$ and $1400 \mathrm{~nm} .{ }^{20}$ The lasers most frequently used for the PBM are the red visible or NIR diode lasers and the more penetrating Nd:YAG lasers. It is important to emphasize that the PBM protocols do not generate heat, smoke or aerosol droplets, which is different from the traditional high-energy surgical laser applications.

Dental professionals are at high risk for nosocomial infections, and they may become potential carriers of the disease. These risks are attributable to the unique nature of dental interventions, which include aerosol generation, the handling of sharp implements, and the proximity of the practitioner to the patient's oropharyngeal region. ${ }^{28}$

Therefore, in the present pandemic condition, the welldocumented and effective anti-inflammatory, regenerative or analgesic applications of PBM may represent an essential tool to face the various emergencies of our patients, although the crucial step of correctly identifying the proper and standardized dosages is not resolved at the moment. However, the wide consensus in the literature concerning its clinical benefits encourages the spread of its use as much as possible in daily clinical practice. The PBM may be used as an adjuvant or alternative therapy in a wide variety of situations, without side effects or drug interactions. ${ }^{29}$

Therefore, practitioners may treat acute diseases, such as recurrent aphthous stomatitis and traumatic ulcers, temporomandibular disorders, recurrent intraoral and labial herpes, oral edema, postoperative pain following periodontal treatments, oral surgery, and endodontic procedures in emergencies using PBM, even in suspected 
or confirmed cases of COVID-19 infection. Similarly, endodontists may be called upon for the assessment and management of odontogenic pain, swelling and dental alveolar traumas, and they may find the support of PBM helpful. ${ }^{28}$

All of the aforementioned considerations should lead researchers and clinicians to dedicate increasing efforts in the identification of precise and standardized PBM protocols to test the impact that this proven and biologically safe therapeutic method could have in treatment during the present COVID-19 pandemic.

\section{Lasers enhancing chemical reactions}

One of the objectives during this pandemic is to decrease the viral load in our patients during dental treatments. There are antecedents in which the use of photodynamic antimicrobial chemotherapy significantly decreased the viral load in different types of oral viruses. ${ }^{30-35}$

Antimicrobial photodynamic therapy (aPDT) is a form of phototherapy that is performed using nontoxic, lightsensitive compounds with selectively exposed/absorbed laser light, which become toxic to target pathogens. The efficacy of PDT was demonstrated in recent clinical research on periopathogens, ${ }^{36-38}$ carious bacteria, ${ }^{39,40}$ onychomycosis, ${ }^{41,42}$ and paracoccidiodomycosis. ${ }^{43}$

Antiviral therapy using laser light, known as photodynamic inactivation (PDI), is based on the same mechanisms as photodynamic antimicrobial chemotherapy (PACT), i.e., non-thermal viral inactivation. We can differentiate 2 types of virus structural damage caused by light - type I and type II photoreactions. Both mechanisms may be active at the same time, but that depends on the photosensitizer (PS), its concentration and the concentration of oxygen. ${ }^{44}$ The PDI can use many compounds with potential photodynamic antiviral activity, ranging from plant extracts (psoralen), eosin, curcumin, and hypericin (St. John's wort), to synthetic compounds. ${ }^{45}$

The sensitivity of viruses to photodynamic therapy was reported for herpes infections, ${ }^{30,31} \mathrm{HPV}$ infections (papillomatosis), ${ }^{32-34}$ cytomegalovirus $\mathrm{CMV},{ }^{35}$ and other viruses. ${ }^{46}$ Many studies showed that enveloped viruses are significantly more sensitive to photodynamic destruction than non-enveloped ones. ${ }^{47}$

To evaluate the sensitivity of the viral photoinactivation process, molecular quantitative methods, such as nucleic acid amplification, including real time polymerase chain reaction (RT-PCR), are needed. This method is sensitive and fast, but it only detects viral nucleic acid, and it does not determine infectivity. Other methods using bacteriophages as surrogates of mammalian viruses may be useful for the quantification of infectivity. ${ }^{25,44}$

Some studies reported reactivation of viruses, such as herpes simplex virus (HSV), after photodynamic treatment as a side effect of PDT. Photo-inactivated viruses still trigger an immune response that may be unwanted, but the treatment is still useful to generate a competent immune response and vaccination. ${ }^{45,48}$ Schikora et al. reported that aPDT mediated by methylene blue and 660-nm red laser light applied to nasal and oral cavities of patients with COVID-19 reduced mortality and comorbidities. $^{49}$

There is no evidence from randomized controlled trials for any specific anti-nCoV treatment. One of the most frequent recommendations during this COVID-19 pandemic is the use of mouth rinses prior to dental treatments with $0.5-1 \% \mathrm{H}_{2} \mathrm{O}_{2}$ or $0.1 \%$ sodium hypochlorite for $1 \mathrm{~min} .^{50,51}$ Other antimicrobial agents, such as $0.02 \%$ chlorhexidine digluconate, are less effective. ${ }^{51}$

Different studies showed that the combination of $\mathrm{H}_{2} \mathrm{O}_{2}$ with a laser produced benefits, especially related to bacterial load. ${ }^{52,53}$ This reduction of microbial viability was demonstrated when combined with diode, neodymium or erbium lasers. Some studies demonstrated that the photoactivation of $3 \% \mathrm{H}_{2} \mathrm{O}_{2}$ with a diode laser increased the bactericidal effect due to the acceleration of hydroxyl radical generation. ${ }^{53,54}$ Laser light activates $\mathrm{H}_{2} \mathrm{O}_{2}$ release of free radicals and singlet oxygen. The stabilized $\mathrm{H}_{2} \mathrm{O}_{2}$ and presence of oxygen allow the reactions of photoactivation and singlet oxygen release, which induce microbial death through the destruction of the bacterial membrane, degradation of the lysosomal membrane, alteration of mitochondrial function, and denaturation of DNA molecules. Caccianiga et al. ${ }^{55}$ reported the successful reduction of periopathogens from implant surfaces in a clinical study using high-level laser therapy (HLLT). These studies demonstrated that the combination of different laser wavelengths $(405 \mathrm{~nm}, 940 \mathrm{~nm}, 980 \mathrm{~nm}, 1064 \mathrm{~nm}$, and $2940 \mathrm{~nm}$ ) with the $\mathrm{H}_{2} \mathrm{O}_{2}$ was much more effective than laser or antioxidant alone. ${ }^{52-57}$ Nammour et al. ${ }^{57}$ performed a randomized clinical study using 980-nm wavelength and $3 \% \mathrm{H}_{2} \mathrm{O}_{2}$, and showed significant clinical improvement and microbiological reduction in a twelve-month follow-up. Grzech-Leśniak et al. ${ }^{56}$ evaluated the effectiveness of treatments with $\mathrm{Nd}$ :YAG laser irradiation and $0.5 \% \mathrm{NaOCl}$ and $0.5 \% \mathrm{H}_{2} \mathrm{O}_{2}$ solutions as single or combined treatment modalities. The authors demonstrated that combined treatment with the Nd:YAG laser at low level laser settings and a low concentration of $\mathrm{H}_{2} \mathrm{O}_{2}(0.5 \%)$ or $\mathrm{NaOCl}(0.5 \%)$ solution effectively reduced the microorganisms. The combination of lasers and $\mathrm{H}_{2} \mathrm{O}_{2}$ may be helpful for viral reduction. The good efficacy of photodynamic viral inactivation has been well-known since its early application in 1973 for the treatment of HSV infections performed by Felber. ${ }^{58}$ The development of medicine increased the treatment options used in dental practice, which now include a wide range of antiviral application portfolios.

Future research on the possibility of destroying SARS COVID-19 using PDI is necessary. 


\section{Specific recommendations for laser dentistry in the SARS-CoV-2 pandemic}

All universal recommendations for general dentistry must be respected, and practitioners must follow their own national recommendations. Additional specific care must be used for lasers, according to the following guidelines:

1. Choose the lowest laser parameters that permit efficient clinical effects and a reduction of air flow. A correct water spray during laser ablation may reduce the aerosol production and viral spread.

2. Face and eyes protection: wear safety glasses/google for each laser wavelength to avoid eye contamination. It is also necessary to use a face shield for splash protection. Use a face mask (e.g., FFP3) to protect the respiratory tract from droplets and smoke plume. ${ }^{59}$

3. Use a rubber dam to avoid viral contamination from the mouth and saliva.

4. Use a high-volume saliva ejector/volume suction system placed at the closest distance to the treated site.

5 . If a smoke plume is produced, use a vacuum system with a high flow volume positioned at the closest distance to the surgical site. The ventilation of the room and disinfection of the dental operating area can effectively limit the transmission of SARS-CoV-2 aerosols.

6. For PBM treatments: The handpieces of the devices are easily protected through the application of transparent removable plastic films to avoid any contact with the skin, mucosa and oral fluids, and permit superficial or deep penetration of the Red/NIR laser beams.

7. Special care must be dedicated to the disinfection of laser devices before and after their use. Handpiece and tips must be autoclaved.

\section{Conclusions}

Even during the present pandemic, all lasers retained their well-known advantages and benefits. However, it is mandatory to know the specific functions and properties of lasers in order to utilize their potential and adapt to the present situation using previously adopted safety recommendations. Moreover, laser light may provide a different path to face the severe health challenges of the current COVID-19 pandemic.

\section{ORCID iDs}

Josep Arnabat-Dominguez (D) https://orcid.org/0000-0003-1653-8043 Alessandro Del Vecchio (D) https://orcid.org/0000-0002-9278-8872 Carmen Todea (1D https://orcid.org/0000-0002-1654-4067 Kinga Grzech-Leśniak (D) https://orcid.org/0000-0002-5700-4577 Paolo Vescovi (D) https://orcid.org/0000-0002-2223-3716 Umberto Romeo (D) https://orcid.org/0000-0003-2439-2187 Samir Nammour (1D) https://orcid.org/0000-0003-0321-9764

\section{References}

1. Guo YR, Cao QD, Hong ZS, et al. The origin, transmission and clinical therapies on coronavirus disease 2019 (COVID-19) outbreak: An update on the status. Mil Med Res. 2020;7(1):1-10. doi:10.1186/ s40779-020-00240-0

2. Dominiak M, Różyło-Kalinowska I, Gedrange T, et al. COVID-19 and professional dental practice. The Polish Dental Association Working Group recommendations for procedures in dental office during an increased epidemiological risk. J Stomatol. 2020;73(1):1-10. doi:10.5114/jos.2020.94168

3. Matys J, Grzech-Leśniak K, Dominiak M. Disinfectants and devices for surface and air disinfection in dental offices. J Stomatol. 2020; 73(4):200-205. doi:10.5114/jos.2020.98267

4. van Doremalen N, Bushmaker T, Morris D, et al. Aerosol and surface stability of SARS-CoV-2 as compared with SARS-CoV-1. NEngl J Med. 2020:382(16):1564-1567. doi:10.1056/NEJMc2004973 \%0A

5. Anfinrud P, Stadnytskyi V, Bax CE, Bax A. Visualizing speech-generated oral fluid droplets with laser light scattering. N Engl J Med. 2020: 382(21):2061-2063. doi:10.1056/nejmc2007800

6. Li RWK, Leung KWC, Sun FCS, Samaranayake LP. Severe acute respiratory syndrome (SARS) and the GDP. Part II: Implications for GDPs. Br Dent J. 2004;197(3):130-134. doi:10.1038/sj.bdj.4811522

7. Hayden C, Bowler JO, Chambers S, et al. Obesity and dental caries in children: A systematic review and meta-analysis. Commun Dent Oral Epidemiol. 2013;41(4):289-308. doi:10.1111/cdoe.12014

8. Wax RS, Christian MD. Practical recommendations for critical care and anesthesiology teams caring for novel coronavirus (2019-nCoV) patients. Can J Anesth. 2020;67(5):568-576. doi:10.1007/s12630-020-01591

9. Romeo U, Libotte F, Palaia G, Tenore G, Galanakis A, Annibali S. Is erbium:yttrium-aluminum-garnet laser versus conventional rotary osteotomy better in the postoperative period for lower third molar surgery? Randomized split-mouth clinical study. J Oral Maxillofac Surg. 2015;73(2):211-218. doi:10.1016/j.joms.2014.08.013

10. Nahen K, Vogel A. Plume dynamics and shielding by the ablation plume during Er:YAG laser ablation. J Biomed Opt. 2002;7(2):165. doi:10.1117/1.1463047

11. Van As G. Erbium lasers in dentistry. Dent Clin North Am. 2004;48(4): 1017-1059. doi:10.1016/j.cden.2004.06.001

12. Garden JM, Kerry O'Banion M, Bakus AD, Olson C. Viral disease transmitted by laser-generated plume (aerosol). Arch Dermatol. 2002; 138(10):1303-1307. doi:10.1001/archderm.138.10.1303

13. Ziegler BL, Thomas CA, Meier T, Müller R, Fliedner TM, Weber L. Generation of infectious retrovirus aerosol through medical laser irradiation. Lasers Surg Med. 1998;22(1):37-41. doi:10.1002/(SICI)1096-9101 (1998)22:1<37:AID-LSM9>3.0.CO;2-Y

14. Palaia G, Pergolini D, D'Alessandro L, et al. Histological effects of an innovative $445 \mathrm{Nm}$ blue laser during oral soft tissue biopsy. Int JEnviron Res Public Health. 2020;17(8):2651. doi:10.3390/ijerph17082651

15. Miyazaki $\mathrm{H}$, Ohshiro $T$, Romeo $U$, et al. Retrospective study on laser treatment of oral vascular lesions using the "leopard technique": The multiple spot irradiation technique with a single-pulsed wave. Photomed Laser Surg. 2018;36(6):320-325. doi:10.1089/pho.2017.4410

16. Garden JM, O'Banion MK, Shelnitz LS, et al. Papillomavirus in the vapor of carbon dioxide laser-treated Verrucae. JAMA. 1988;259(8); 1199-1202.

17. Sawchuk WS, Weber PJ, Lowy DR, Dzubow LM. Infectious papillomavirus in the vapor of warts treated with carbon dioxide laser or electrocoagulation: Detection and protection. J Am Acad Dermatol. 1989; 21(1):41-49. doi:10.1016/s0190-9622(89)70146-8

18. Hallmo P, Naess O. Laryngeal papillomatosis with human papillomavirus DNA contracted by a laser surgeon. Eur Arch Otorhinolaryngol. 1991;248(7):425-427. doi:10.1007/BF01463570

19. Hughes PSH, Hughes AP. Absence of human papillomavirus DNA in the plume of erbium: YAG laser-treated warts. J Am Acad Dermatol. 1998;38(3):426-428. doi:10.1016/S0190-9622(98)70500-6

20. Hamblin MR. Mechanisms and mitochondrial redox signaling in photobiomodulation. Photochem Photobiol. 2018;94(2):199-212. doi:10. 1111/php.12864

21. Grzech-Leśniak K, Nowicka J, Pajączkowska M, et al. Effects of Nd:YAG laser irradiation on the growth of Candida albicans and Streptococcus mutans: In vitro study. Lasers Med Sci. 2019;34(1):129-137. doi:10.1007/ s10103-018-2622-6 
22. Dompe C, Moncrieff L, Matys J, et al. Photobiomodulation-underlying mechanism and clinical applications. J Clin Med. 2020;9(6):1724. doi:10.3390/jcm906172421

23. Enwemeka CS, Bumah VV, Masson-Meyers DS. Light as a potential treatment for pandemic coronavirus infections: A perspective. J Photochem Photobiol B. 2020;207:111891. doi:10.1016/j.jphotobiol.2020. 111891

24. Tsen S, Chapa T, Beatty W, Xu B, Tsen K, Achilefu S. Ultrashort pulsed laser treatment inactivates viruses by inhibiting viral replication and transcription in the host nucleus. Antiviral Res. 2014;110:70-76. doi:10. 1016/j.antiviral.2014.07.012

25. Zupin L, Caracciolo I, Tricarico PM, Ottaviani G, D’Agaro P, Crovella S. Photobiomodulation therapy reduces viral load and cell death in ZIKVinfected glioblastoma cell line. Lasers Med Sci. 2018;33(9):2011-2013. doi:10.1007/s10103-018-2568-8

26. Domínguez A, Velásquez SA, David MA. Can transdermal photobiomodulation help us at the time of COVID-19? Photobiomodul Photomed Laser Surg. 2020;38(5):258-259. doi:10.1089/photob.2020.4870

27. Szymczyszyn A, Doroszko A, Szahidewicz-Krupska E, et al. Effect of the transdermal low-level laser therapy on endothelial function. Lasers Med Sci. 2016;31(7):1301-1307. doi:10.1007/s10103-016-1971-2

28. Ather A, Patel B, Ruparel NB, Diogenes A, Hargreaves KM. Coronavirus disease 19 (COVID-19): Implications for clinical dental care. J Endod. 2020;46(5):584-595. doi:10.1016/j.joen.2020.03.008

29. Fekrazad R. Photobiomodulation and antiviral photodynamic therapy as a possible novel approach in COVID-19 management. Photobiomodul Photomed Laser Surg. 2020;38(5):255-257. doi:10.1089/photob. 2020.4868

30. Namvar MA, Vahedi M, Abdolsamadi H, Mirzaei A, Mohammadi Y, Aziz Jalilian F. Effect of photodynamic therapy by 810 and $940 \mathrm{~nm}$ diode laser on Herpes Simplex Virus 1: An in vitro study. Photodiagnosis Photodyn Ther. 2019;25:87-91. doi:10.1016/j.pdpdt.2018.11.011

31. La Selva A, Negreiros RM, Bezerra DT, et al. Treatment of herpes labialis by photodynamic therapy. Medicine (Baltimore). 2020;99(12):e19500. doi:10.1097/md.0000000000019500

32. Zhang W, Zhang A, Sun W, Yue Y, Li H. Efficacy and safety of photodynamic therapy for cervical intraepithelial neoplasia and human papilloma virus infection: A systematic review and meta-analysis of randomized clinical trials. Medicine (Baltimore). 2018;97(21):e10864. doi:10.1097/MD.0000000000010864

33. Shikowitz MJ, Abramson AL, Freeman K, Steinberg BM, Nouri M. Efficacy of DHE photodynamic therapy for respiratory papillomatosis: Immediate and long-term results. Laryngoscope. 1998;108(7):962-967. doi:10.1097/00005537-199807000-00002

34. Abramson AL, Shikowitz MJ, Mullooly VM, Steinberg BM, Amella CA, Rothstein HR. Clinical effects of photodynamic therapy on recurrent laryngeal papillomas. Arch Otolaryngol Neck Surg. 1992;118(1):25-29. doi:10.1001/archotol.1992.01880010029011

35. Belousova IM, Kislyakov IM, Muraviova TD, et al. Photodynamic inactivation of enveloped virus in protein plasma preparations by solidphase fullerene-based photosensitizer. Photodiagnosis Photodyn Ther. 2014;11(2):165-170. doi:10.1016/j.pdpdt.2014.02.009

36. Grzech-Leśniak K, Gaspirc B, Sculean A. Clinical and microbiological effects of multiple applications of antibacterial photodynamic therapy in periodontal maintenance patients: A randomized controlled clinical study. Photodiagnosis Photodyn Ther. 2019;27(5):44-50. doi:10.1016/j.pdpdt.2019.05.028

37. Grzech-Leśniak K, Matys J, Dominiak M. Comparison of the clinical and microbiological effects of antibiotic therapy in periodontal pockets following laser treatment: An in vivo study. Adv Clin Exp Med. 2018;27(9):1263-1270. doi:10.17219/acem/70413

38. Świder K, Dominiak M, Grzech-Leśniak K, Matys J. Effect of different laser wavelengths on periodontopathogens in peri-implantitis: A review of in vivo studies. Microorganisms. 2019;7(7):189. doi:10.3390/ microorganisms7070189

39. Alves LVGL, Curylofo-Zotti FA, Borsatto MC, et al. Influence of antimicrobial photodynamic therapy in carious lesion: Randomized splitmouth clinical trial in primary molars. Photodiagnosis Photodyn Ther. 2019;26(11):124-130. doi:10.1016/j.pdpdt.2019.02.018

40. Bargrizan M, Fekrazad R, Goudarzi N, Goudarzi N. Effects of antibacterial photodynamic therapy on salivary mutans streptococci in 5- to 6-year-olds with severe early childhood caries. Lasers Med Sci. 2019;34(3):433-440. doi:10.1007/s10103-018-2650-2
41. Alberdi E, Gómez C. Efficiency of methylene blue-mediated photodynamic therapy vs intense pulsed light in the treatment of onychomycosis in the toenails. Photodermatol Photoimmunol Photomed. 2019;35(2):69-77. doi:10.1111/phpp.12420

42. Koren A, Salameh F, Sprecher E, Artzi O. Laser-assisted photodynamic therapy or laser-assisted amorolfine lacquer delivery for treatment of toenail onychomycosis: An open-label comparative study. Acta Derm Venereol. 2018;98(4):467-468. doi:10.2340/00015555-2874

43. dos Santos LFM, Melo NB, de Carli ML, et al. Photodynamic inactivation of Paracoccidioides brasiliensis helps the outcome of oral paracoccidiodomycosis. Lasers Med Sci. 2017;32(4):921-930. doi:10.1007/ s10103-017-2193-y

44. Costa L, Faustino MAF, Tomé JPC, et al. Involvement of type I and type II mechanisms on the photoinactivation of non-enveloped DNA and RNA bacteriophages. J Photochem Photobiol B. 2013;120:10-16. doi:10.1016/j.jphotobiol.2013.01.005

45. Wiehe A, O'Brien JM, Senge MO. Trends and targets in antiviral phototherapy. Photochem Photobiol Sci. 2019;18(11):2565-2612. doi:10.1039/ c9pp00211a

46. Tsen SWD, Kingsley DH, Poweleit C, et al. Studies of inactivation mechanism of non-enveloped icosahedral virus by a visible ultrashort pulsed laser. Virol J. 2014;11(1):1-9. doi:10.1186/1743-422X-11-20

47. Costa L, Faustino MAF, Neves MGPMS, Cunha Â, Almeida A. Photodynamic inactivation of mammalian viruses and bacteriophages. Viruses. 2012;4(7):1034-1074. doi:10.3390/v4071034

48. Schneider K, Wronka-Edwards L, Leggett-Embrey M, et al. Psoralen inactivation of viruses: A process for the safe manipulation of viral antigen and nucleic acid. Viruses. 2015;7(11):5875-5888. doi:10.3390/ v7112912

49. Schikora J, Hepburn J, Plavin SR. Reduction of the viral load by noninvasive photodynamic therapy in early stages of COVID-19 infection. Am J Vir Dis. 2020; 2(1):01-05.

50. Kampf G. Potential role of inanimate surfaces for the spread of coronaviruses and their inactivation with disinfectant agents. Infect Prev Pract. 2020;2(2):100044. doi:10.1016/j.infpip.2020.100044

51. Pratelli A. Action of disinfectants on canine coronavirus replication in vitro. Zoonoses Public Health. 2007;54(9-10):383-386. doi:10.1111/ j.1863-2378.2007.01079.x

52. Deeb JG, Smith J, Belvin BR, Grzech-Leśniak K, Lewis J. Er:YAG laser irradiation reduces microbial viability when used in combination with irrigation with sodium hypochlorite, chlorhexidine, and hydrogen peroxide. Microorganisms. 2019;7(12):612. doi:10.3390/microorganisms7120612

53. Odor AA, Bechir ES, Violant D, Badea V. Antimicrobial effect of $940 \mathrm{~nm}$ diode laser based on photolysis of hydrogen peroxide in the treatment of periodontal disease. Rev Chim. 2018;69(8):2081-2088. doi:10. 37358/rc.18.8.6478

54. Kanno T, Nakamura K, Ishiyama K, et al. Adjunctive antimicrobial chemotherapy based on hydrogen peroxide photolysis for non-surgical treatment of moderate to severe periodontitis: A randomized controlled trial. Sci Rep. 2017;7(1):12247. doi:10.1038/s41598-017-12514-0

55. Caccianiga G, Rey G, Baldoni M, Paiusco A. Clinical, radiographic and microbiological evaluation of high level laser therapy, a new photodynamic therapy protocol, in peri-implantitis treatment: A pilot experience. Biomed Res Int. 2016;2016:6321906. doi:10.1155/2016/6321906

56. Grzech-Leśniak K, Belvin BR, Lewis PJ, Golob Deeb J. Treatment with $\mathrm{Nd}$ YYA laser irradiation combined with sodium hypochlorite or hydrogen peroxide irrigation on periodontal pathogens: An in vitro study. Photobiomodul Photomed Laser Surg. 2021;39(1):46-52. doi:10.1089/ pho.2019.4775

57. Nammour S, El Mobadder M, Maalouf E, et al. Clinical evaluation of diode $(980 \mathrm{~nm})$ laser-assisted nonsurgical periodontal pocket therapy: A randomized comparative clinical trial and bacteriological study. Photobiomodul Photomed Laser Surg. 2021;39(1):10-22. doi:10. 1089/photob.2020.4818. doi:10.1089/photob.2020.4818

58. Wainwright M. Local treatment of viral disease using photodynamic therapy. Int J Antimicrob Agents. 2003;21(6):510-520. doi:10.1016/ S0924-8579(03)00035-9

59. Ramanathan K, Antognini D, Combes A, Douthwaite S, Goldenberg SD, Weber DJ. Transmission of SARS and MERS coronaviruses and influenza virus in healthcare settings: The possible role of dry surface contamination. J Hosp Infect. 2020;92(3):235-250. 